\title{
EVALUATION OF MECHANICAL PROPERTIES OF E-GLASS AND COCONUT FIBER REINFORCED WITH POLYESTER AND EPOXY RESIN MATRICES
}

\author{
R.D. HEMANTH ${ }^{1}$, M. SENTHIL KUMAR ${ }^{2}$, AJITH GOPINATH ${ }^{3} \&$ L. NATRAYAN ${ }^{4}$ \\ ${ }^{1,2,4}$ SMBS, VIT University, Chennai, Tamil Nadu, India \\ ${ }^{3}$ Department of Mechanical Engineering, Christ University, Bangalore, India
}

\begin{abstract}
Composite manufacturing is the novel branch of science, which finds its immense applications in various industries such as sporting, automotive, aerospace and marine industries. The superior properties of composites such as stiffness, better mechanical properties, low density and light weight make it a candidate in engineering applications. The need for seeking alternate materials with increased performance in the field of composites revived this research, to prepare fiber reinforced composites by hand layup method using E-glass and coconut fibers with length 5-6 $\mathrm{mm}$. The resin used in the preparation of composites was epoxy and polyester. Fiber reinforced composites were synthesized at 18:82 fiber-resin weight percentages. Samples prepared were tested to evaluate its mechanical and physical properties, such as tensile strength, flexural strength, impact strength, hardness and scanning electron microscope (SEM). Scanning electron microscope analysis revealed the morphological features. E-glass fiber reinforced epoxy composite exhibited better mechanical properties than other composite samples. The cross linking density of monomers of the epoxy resin and addition of the short chopped $E$-glass fibers enhanced the properties of $E$-glass epoxy fiber reinforced composite.

KEYWORDS: Aerospace, Stiffness, Weight Percentage, Microstructural Study \& Morphological Features
\end{abstract}

Received: Jul 25, 2017; Accepted: Aug 16, 2017; Published: Aug 23, 2017; Paper Id.: IJMPERDOCT20172

\section{INTRODUCTION}

In modern engineering applications, fiber reinforced plastics are used widely in aircraft and spacecraft structural parts due to its mechanical and physical properties like high specific strength and specific stiffness. Though there are different thermoset materials available as resin, still epoxy remains as a choice due to its ability to obtain desired chemical and mechanical properties [1]. The composites are usually made using artificial and natural fibers. Artificial fibers such as glass, carbon, and aramid offer the advantages of higher stiffness and strength to weight ratio [2]. Among this glass fiber stands out as a lightweight, strong, and robust material in different industries due to their excellent properties [3]. Despite these advantages, the use of synthetic fiber reinforced polymer composites in automotive applications is growing [4].

The mechanical properties of randomly oriented E-glass fiber reinforced epoxy such as flexural and tensile strength increased with increase in weight fraction of the fiber [5]. Brittleness also increased with increase in weight percentage, which reported a decrease in the impact energy [6]. E-glass, along with various resins like epoxy, polyester, vinyl ester, evaluated for its different properties found mechanical stress concentrations were a greater threat to brittle fracture [7]. However, brittle fracture can be successfully eliminated, or at least unnaturally reduced, by the correct chemical optimization of composite to stress deterioration cracking [8]. Tensile properties of Kevlar/Glass- Epoxy Hybrid Composite across and along the fiber direction were found to be tougher along the fiber direction, than across the direction of the fibers [9]. An attempt was made to develop a natural and artificial 
fiber reinforced hybrid composite material with finest properties to substitute the existing synthetic fiber reinforced composite material in automobile leaf spring. Jute and E-glass woven roving mats are used as reinforcements and epoxy resin is used as the matrix material [10].

Tensile strength (TS) of short-fiber-reinforced polymers (SFRP), was derived as a function of fiber length and fiber orientation distribution [11].Out of various natural fibers investigated for their use in plastics, some of them like kenaf, ramie, Flax, hemp, sisal, coir, jute, straw, wood fiber, oil palm, rice husks, wheat, barley, oats, cane (sugar and bamboo), empty fruit bunch, water pennywort, kapok, banana fiber, pineapple leaf fiber, paper-mulberry, raphia and papyrus, grass reeds are used very commonly for researches[12]. Their applications have increased extraordinarily as a consequence of which, the use has also increased extensively. Natural fibers have the advantage of cost savings and reduction in density compared to glass fibers [13]. As the manufacturing of natural fibers is cheap and environment friendly, it can be measured as a substitute source to synthetic fibers. The uses and applications of jute and banana fiber composites are discussed in detail [14].

Jute fiber, due to its easy availability and commercial nature revealed moderate mechanical properties. But, by treating the fiber in alkali medium mechanical property can be enhanced [15]. Tensile strength of oriented discontinuous fiber composites was evaluated by single fiber pull out showed the fiber/matrix adhesion was good due to the natural waxy surface [16]. Tensile and flexural strength of pineapple leaf fiber reinforced polypropylene composites as a function of volume fraction were found to be increasing with fiber content, in accordance with the rule of mixtures [17]. Straw reinforced polyester composites with volume fraction of $40 \%$ resulted in high tensile strength $104 \mathrm{MPa}$ [18]. kenaf fiberreinforced composites tensile and flexural strength has increased linearly with fiber content up to 50\% [19].

The literature study shows that the composites importance in numerous diverse areas such as automobile, structural, aerospace and marine applications. Reviews confirm very few researches have been carried out in the effects of fiber properties on the mechanical performance of the polymer composites. Development of a high-performance composite using natural and artificial fibers has been a major area of concern. This research studies the mechanical and physical properties of both natural and artificial fiber reinforced composite (E-glass and coconut fiber). The fiber reinforced composites were synthesized by using E-glass and coconut reinforced with epoxy and polyester resin. The prepared composites were subjected to hardness, flexural strength, impact, tensile test and SEM.

\section{EXPERIMENTAL PROCEDURE}

E-glass and coconut fibers of length 5-6 mm were used for preparing fiber reinforced composites. Fiber reinforced composites were synthesized at 18:82 fiber-resin weight percentages. The synthesis of E-glass composites and coconut fiber reinforced composites with different resins used in this research. Tri ethylene tetra amine (TETA) was used as the hardener for epoxy resin, and whereas for polyester methyl ethyl ketone peroxide (MEKPO) was used. The specimen was prepared by using hand layup method. Fibers in required weight percentages were added to the resin and mixed properly. The mixture was added with the respective hardener and then poured into mould and were allowed to set for 24 hours. The specimens were prepared according to ASTM test standards. Tensile test was carried out as per the ASTM D3039 standard using a Shimadzu universal testing machine (UTM) setup to determine the tensile strength. Flexural strength of the fiber reinforced composites was determined by conducting three point bend tests on the specimen in UTM (ASTM D790). Impact energy was determined by conducting charpy test (ASTM A370) notched in the middle at 45 degrees. Rockwell hardness test was carried out at 100kg applied load using the indenter of 1/16" with chosen M scale. 


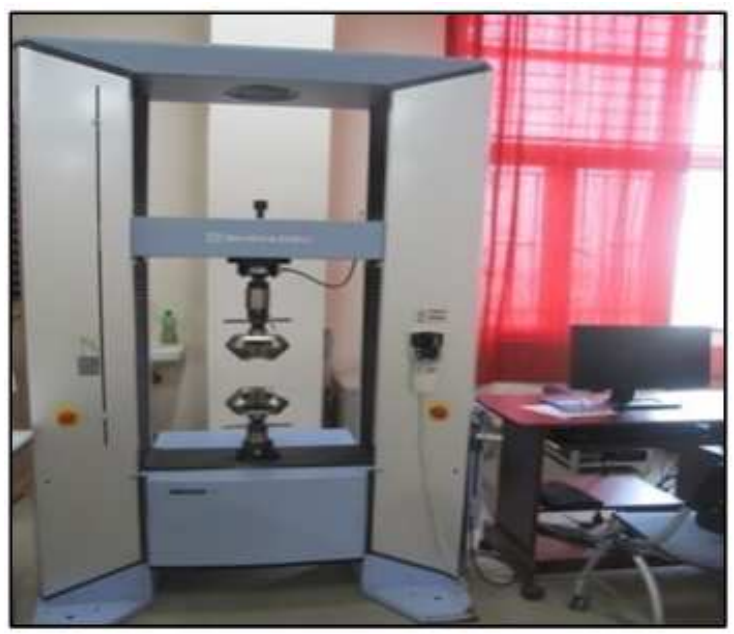

Figure 1: Tensile Test Setup Shimadzu Universal Testing Machine

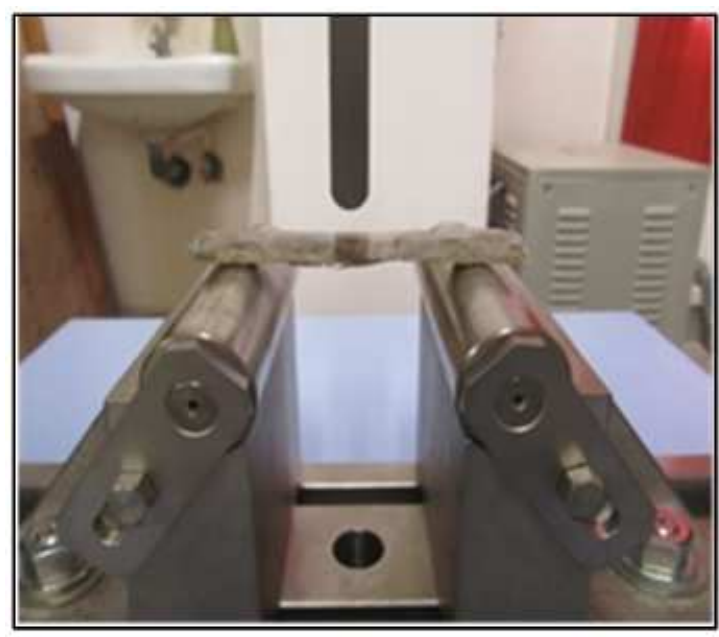

Figure 2: Flexural Test Setup Shimadzu Universal Testing Machine

\section{RESULTS AND DISCUSSIONS}

Fiber reinforced composite specimens prepared were subjected to tensile, flexural, hardness and impact tests. The obtained results were analyzed, compared and conclusions were derived from the same. E-glass fiber reinforced epoxy matrix composites showed better mechanical properties in all the tests results. The coconut fibers being biodegradable revealed considerably good mechanical properties.

\section{Tensile Test}

Test results confirmed, coconut fiber epoxy composites exhibited maximum tensile strength compared to coconut fiber polyester, this may be due to the restriction of the mobility and deformability of the matrix. Ultimate stress and the fracture point are visible from the stress strain plot shown in Figure 2. Young's modulus of composite specimen calculated shows good value of $3.117 \mathrm{GPa}$ for the E-glass-epoxy composites (Table 1). Tensile strength and young's modulus for composite specimens were estimated from the ultimate load values in load displacement graph. The tensile strength and young's modulus for E-glass-epoxy composites were calculated based on the equation. Tensile load of glass composite is found to be high (Table 1). It is found that tensile load of epoxy E-glass composite is higher than polyester coconut composite.

The percentage elongation of coconut-glass fiber reinforced composite is found to be higher than the other composites, and hence it may have more ductile property in nature.

$$
\begin{aligned}
& \sigma_{\mathrm{t}}=\mathrm{P} / \mathrm{bh} \\
& \sigma_{\mathrm{t}}=2431.36 /(12 \times 5)=40.53 \mathrm{MPa}
\end{aligned}
$$

Young's modulus $=$ Tensile stress $/$ Tensile strain

$$
\mathrm{E}=40.53 / .013=3.117 \mathrm{GPa}
$$




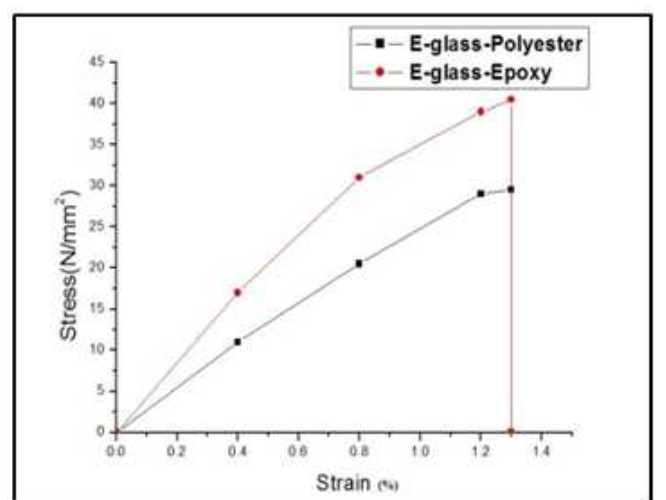

Figure 3: Tensile Stress Strain Plot of E-Glass Fiber Reinforced Polymer Composites

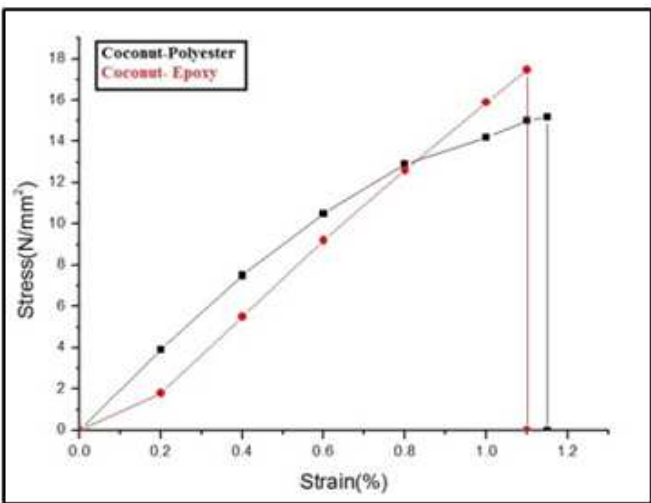

Figure 4: Tensile Stress Strain Plot for Coconut Fiber Reinforced Polymer Composites

Figure 3 indicates the stress strain plot for E-glass and coconut fiber reinforced composites. It is evident from the curve that the composites showed brittle nature as they reached the rupture point abruptly without any sign of neck formation. The strength of coconut fiber reinforced composites and E-glass fiber reinforced composites shows the dynamic characteristics of composite indicating load transfer characteristics.

Table 1: Tensile Test Results for E-Glass and Coconut Fiber Reinforced Polymer Matrices

\begin{tabular}{|l|c|c|c|c|}
\hline \multicolumn{1}{|c|}{ Tensile Properties } & \multicolumn{2}{c|}{ E-Glass } & \multicolumn{2}{c|}{ Coconut } \\
\hline \multicolumn{1}{|c|}{ Fiber } & Epoxy & Polyester & Epoxy & Polyester \\
\hline Tensile strength (MPa) & 40.53 & 28.87 & 17.43 & 14.8 \\
\hline Young's Modulus (GPa) & 3.117 & 2.406 & 1.584 & 0.986 \\
\hline Maximum Strain & .013 & .012 & .011 & .015 \\
\hline Maximum stress (MPa) & 40.53 & 28.87 & 17.43 & 14.8 \\
\hline Maximum Load (N) & 2431.36 & 1732.34 & 1046 & 888 \\
\hline
\end{tabular}

\section{Flexural Test}

Flexural strength of composites is presented in Table 2. E-glass epoxy specimen resisted a flexural load of 532.65 $\mathrm{N}$ before succumbing to it. The ultimate loads for the E-glass-polyester, coconut-epoxy, and coconut polyester fiber reinforced composites were $306.81 \mathrm{~N}, 108.44 \mathrm{~N}, 108.337 \mathrm{~N}$ respectively. But, incorporation of long fiber into the composite reduced the workability thus introduced voids Flexural load was always found to be higher than the tensile load due to orientation of fibers. Presence of a small crack in composites subjected to tensile test will also act as a stress concentrating factor. Tensile load being applied will pull the fibers out easily. But, in flexural testing the load applied is perpendicular to the cross section of specimen. Hence, the load resisted by the specimen is always higher than the tensile testing. E-glass epoxy composite was found to show superior flexural strength and flexural modulus (177.37 MPa and 11.09 GPa). Flexural modulus was calculated using by the formula given in the equations 3 and 4.

$$
\begin{aligned}
& \sigma \mathrm{f}=3 \mathrm{PL} / 2 \mathrm{bh} 2 \\
& \sigma \mathrm{f}=3 \times 532.65 \times 80 /(2 \times 10 \times 62)=177.37 \mathrm{MPa}
\end{aligned}
$$

Flexural modulus $=\mathrm{L} 3 \mathrm{~m} / 4 \mathrm{bh} 3$

The calculated flexural modulus of E-glass polyester composite was $6.391 \mathrm{GPa}$, whereas it is 1.291 and 2.777 GPa for coconut-epoxy and coconut-polyester composites. Flexural modulus gave a measure of the stiffness of the 
material. The materials with higher value of flexural modulus are said to be stiffer, and hence will be of brittle nature. The flexural modulus of ductile materials is found to be generally lower than that of brittle materials.

Table 2: Flexural Test Results for E-Glass and Coconut Fiber Reinforced Polymer Matrices

\begin{tabular}{|l|c|c|c|c|}
\hline \multicolumn{1}{|c|}{ Flexural Properties } & \multicolumn{2}{c|}{ E-Glass } & \multicolumn{2}{c|}{ Coconut } \\
\hline \multicolumn{1}{|c|}{ Resin } & Epoxy & Polyester & Epoxy & Polyester \\
\hline Flexural strength(N/mm $\left.{ }^{2}\right)$ & 177.37 & 102.27 & 36.15 & 36.11 \\
\hline Flexural Modulus $(\mathrm{GPa})$ & 11.09 & 6.391 & 1.291 & 2.777 \\
\hline Maximum Flexural strain & .015 & .016 & .028 & .013 \\
\hline Maximum stress $\left(\mathrm{N} / \mathrm{mm}^{2}\right)$ & 177.37 & 102.27 & 36.15 & 36.11 \\
\hline Maximum Load(N) & 532.65 & 306.81 & 108.44 & 108.337 \\
\hline
\end{tabular}

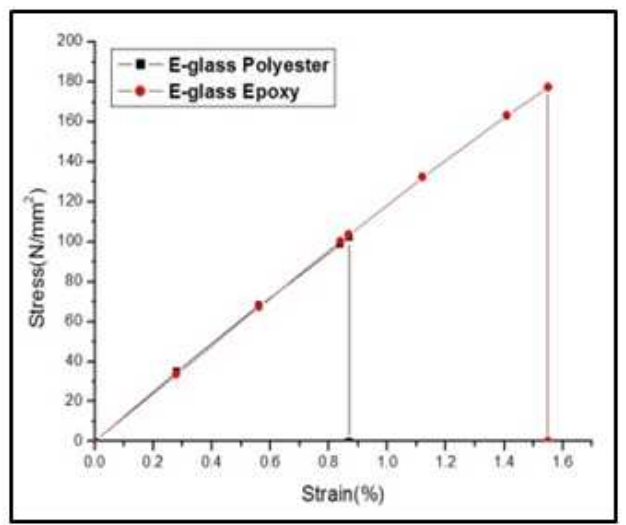

Figure 5: Flexural Stress Strain Plot of E-Glass Fiber Reinforced Polymer Composites

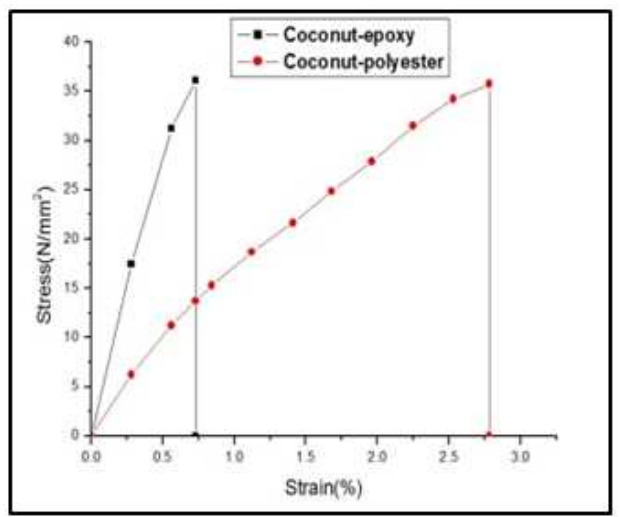

Figure 6: Flexural Stress Strain Plot for Coconut Fiber Reinforced Polymer Composites

Flexural test generally helps determine the degree of brittleness of the material. The brittle materials tend to break abruptly without any specific warning, where as in ductile fracture the symptoms of breakage are visible before the fracture point. During the bending stress if the fibers at the sides are strong then they resist the fracture. Breaking load of glass composite is found to be higher than the coconut composites. The breaking load of epoxy E-glass composite is 1.73 times higher than polyester E-glass composite and 4.9 times higher than epoxy coconut fiber composite. The elongation percentage of coir-glass composite is found to be greater than other composites, hence it is found to have higher ductility. From the results of the tensile test, it can be concluded that the epoxy E-glass composite has better performance compared to other types of composites.

\section{Microstructural Study}

Figure 7 shows the SEM images of fracture surfaces. It was observed that the uneven matrix cracking and void formation reduced in treated coir than the untreated coir. This is due to the good laminar bond between treated coir and resins. The treated coir fibers restricted the applied flexural load better than untreated coir fibers. It was found to have good interfacial bonding and no micro cracks which has given the composite little positive strength. Coir fibers exhibited greater improvement of impact strength due to the removal of hemicelluloses and impurities in the fiber treatment process. SEM analysis showed that the interfacial bonding adhesion between the fiber and polyester matrix as considerably good, when compare to epoxy matrix and also the curing time of the polyester resin is less than the epoxy resin. Fiber pullout is visible, which clearly indicate the improper fiber-matrix adhesion. This leads to a considerable reduction in the strength of the composites (Figure 8). Though matrix is responsible for the uniform stress transfer, the air voids inside the resin is one of 
the main reasons for reduction in strength of the composite
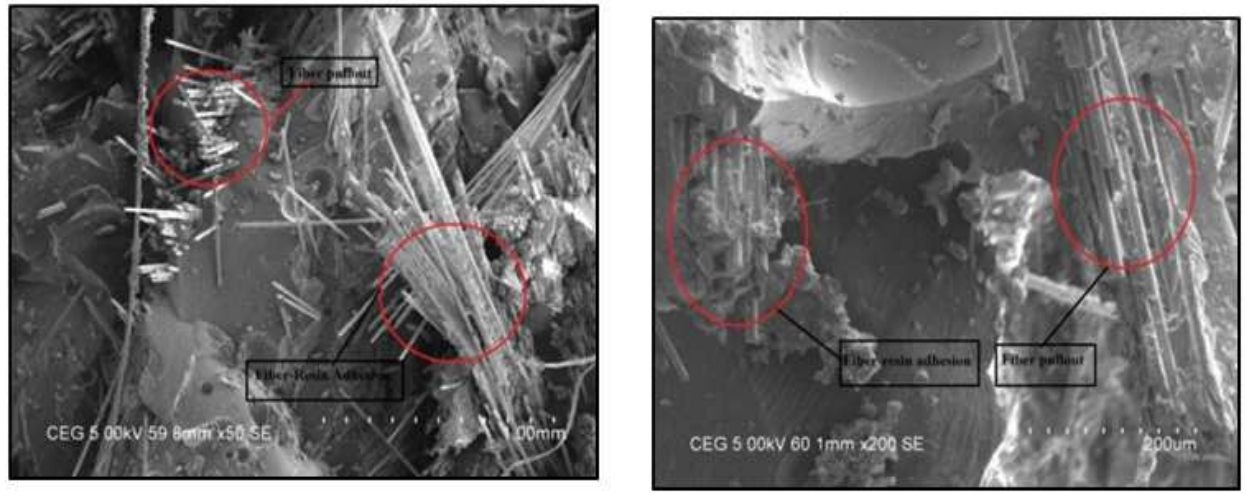

Figure 7: SEM Image for E-Glass Reinforced Polyester Composite

\section{Impact Test}

Charpy test is conducted for determining the impact energy of the composites to study the resistance of the specimen against shocks. The energy absorbed by the specimen to failure was obtained in joules. The obtained energy in joules indicates the resistance of the material to shock loads. The specimens prepared according to the ASTMA370 standards $(55 \times 10 \times 10 \mathrm{~mm})$ were used for this process. Comparatively lower values obtained for the impact test in the coconut fiber reinforced composites was due to the brittle nature of the composites (Figure 5). The epoxy E-glass composite has high impact strength. Energy absorbed by each specimen when it is subjected to heavy impact blow from pendulum, the crack formation happens. The crack usually transferred through the fiber and resin of the composite. So, when crack travels through the composite absorption of energy will be high. The breaking load of Glass fiber reinforced composite is found to be high $(5.8 \mathrm{KN})$. It is found that breaking load of Epoxy E-glass fiber reinforced composite is 1.93 times higher than epoxy coconut fiber reinforced composite and 2.07 times higher than polyester coconut fiber reinforced composite.

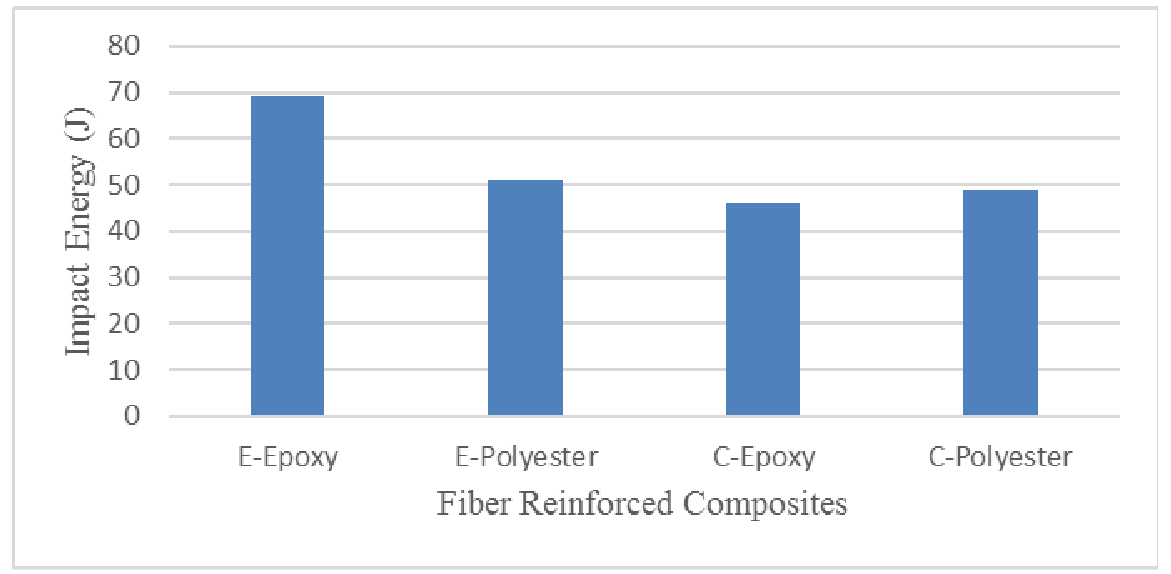

Figure 8: Impact Test Results for E-Glass \& Coconut Fiber Reinforced Polymer Matrices

\section{Hardness Test}

Hardness test is performed with a ball indenter 1/16" with an applied load of 100. Tests results showed that the Eglass fiber reinforced epoxy composites have the highest hardness value. The results indicate that more than the fiber, the 
resin plays an important role in determining the hardness of the material. As shown in Figure 6, the average hardness value of E-glass fiber reinforced epoxy composites were found to be 68.2, it showed highest hardness. This is due to the fact that the matrix material increased proportionately to bond with the resin.

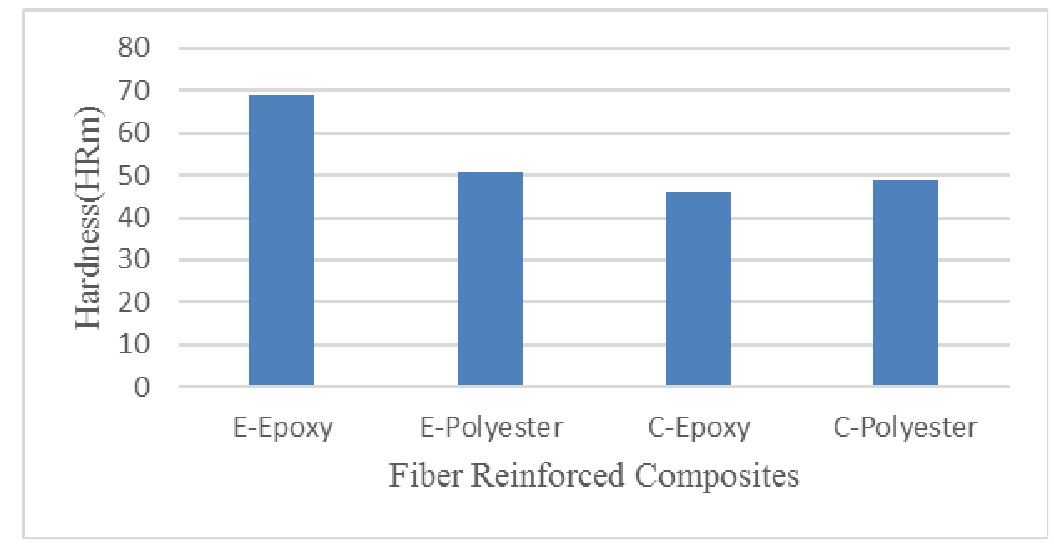

Figure 9: Rockwell Hardness Test Results for E-Glass and Coconut Fiber Reinforced Polymer Matrices

\section{CONCLUSIONS}

E-glass and coconut fiber reinforced epoxy and polyester composites were successfully prepared. The prepared specimens were subjected to mechanical and microstructural characterization. Based on the obtained results, following were the conclusions. Investigations showed the potential use of coconut fiber reinforced polyethylene composite with good stiffness, but with a limitation in the strength lesser than glass fiber composite

E-glass reinforced epoxy resin composites showed better mechanical properties. E-glass epoxy composites showed a tensile strength of $40.53 \mathrm{MPa}$, flexural strength of $177.37 \mathrm{MPa}$, impact strength of $5.75 \mathrm{~J}$, and hardness value of 68.2 HRm. The obtained results of coconut fiber reinforced composites cannot be ignored. From the investigation, it shows potential use of coconut fiber reinforced composites with good stiffness, but with a limitation in strength.

\section{ACKNOWLEDGEMENTS}

The authors express their thanks to Management, Dean-SMBS, VIT University for providing their facilities to carry out this research.

\section{REFERENCES}

1. Muhannad Z. Khelifa, Hayder Moasa Al-Shukri "Fatigue Study Of E-Glass Fiber Reinforced Polyester Composite Under Fully Reversed Loading And Spectrum Loading” Eng. \& Technology, Vol.26, No.10, 2008..

2. Elsayed A. Elbadry, Mohamed S. Aly-Hassan, and Hiroyuki Hamada "Mechanical Properties of Natural Jute Fabric/JuteMat Fiber Reinforced Polymer Matrix Hybrid Composites" Advances in Mechanical Engineering Volume 2012, Article ID 354547 , September 2012.

3. Mahmood M Shokrieha, Mohammad A Torabizadeh, Abdolhossein Fereidoon "Dynamic failure behavior of glass/epoxy composites under low temperature using Charpy impact test method" Indian Journal of Engineering \& Materials Sciences Vol. 18, June 2011, pp. 211-220.

4. C. C. Chamis and J. H. Sinclair "Impact Resistance of Fiber Composites: Energy absorbing Mechanisms and Environmental Effects” NASA Technical Memorandum 83594 
5. K. Devendra, T. Rangaswamy "Evaluation of Thermal Properties of E-Glass/ Epoxy Composites Filled by Different Filler Materials” International Journal of Computational Engineering Research (ijceronline.com) Vol. 2, Issue.5.

6. Satnam Singh, Pardeep Kumar, S.K. Jain "An experimental and numerical investigation of mechanical properties of glass fiber reinforced epoxy composites" Adv. Mat. Lett. 2013, 4(7), 567-572.

7. B. Mobasher, D. Kingsbury, J. Montesinos, and R. S. Gorur "Mechanical Aspects of Crimped Glass Reinforced Plastic (GRP) Rods" ieee transactions on power delivery, vol. 18, no. 3, july 2003.

8. Lucas S. Kumosa, Maciej S. Kumosa, and Daniel L. Armentrout "Resistance to Brittle Fracture of Glass Reinforced Polymer Composites Used in Composite (Nonceramic) Insulators” ieee transactions on power delivery, vol. 20, no. 4, October 2005.

9. Amrita Srivastava, Sanjay Choudhary "Design and Structural Analysis of Jute/E-glass Woven Fiber Reinforced Epoxy Based Hybrid Composite Leaf Spring under Static Loading” International Journal of Mechanical Engineering and Research. ISSN 2249-0019, Volume 3, Number 6 (2013), pp. 573-582.

10. Satish Pujari, A. Ramakrishna, M. Suresh Kumar "Comparison of Jute and Banana Fiber Composites: A Review" International Journal of Current Engineering and Technology, P-ISSN 2347 - 5161, 2014.

11. Shao-Yun Fu \& Bernd Lauke "Effects of fiber length and fiber orientation distributions on the tensile strength of short-fiberreinforced polymers" Composites sc ience and Technology 56 (19\%) 1179-1190,1996.

12. Rajmohan T, Koundinya U.K, Arun Premnath A, Harish G "Evaluation of Mechanical Properties of Nano Filled Glass Fiber Reinforced Composites" "international Conference on Advanced Nanomaterial's \& Emerging Engineering Technologies July, 2013

13. Mohd Aidy Faizal, Yeo Kiam Beng, Mohd Noh Dalimin "tensile property of hand lay-up plain-weave woven e-glass/polyester composite curing pressure and ply arrangement effect" borneo science 2006.

14. Maheswaran, T. Velmurugan, M. Mohammed Mohaideen J "An Experimental and Numerical Study of Fracture Toughness of Kevlar- Glass Epoxy Hybrid Composite” 978-1-4673-6150-7113,2013,IEEE

15. Ajith Gopinath, Senthil Kumar.M, Elayaperumal A, "Experimental Investigations on Mechanical Properties Of Jute Fiber Reinforced Composites with Polyester and Epoxy Resin Matrices”, Procedia Engineering 97 ( 2014 ) 2052 - 2063

16. M. Brahmakumar, C. Pavithran, R.M. Pillai. (2005) "Coconut fibre reinforced polyethylene composites: effect of natural waxy surface layer of the fibre on fibre/matrix interfacial bonding and strength of composites". Composites Science and Technology, 65(3-4), pp 563-569.

17. M.N. Arib, S.M. Sapuan, M.M.H.M. Ahmad, M.T. Paridah, H.M.D. Khairul Zaman. (2006) "Mechanical properties of pineapple leaf fiber reinforced polypropylene composites". Materials and Design, 27(5), pp 391-396.

18. Ratna Prasad, K. Murali Mohan Rao. (2007) “Tensile and impact behaviour of Rice straw polyester composites”, 32 (4), pp 399-403.

19. Shinji Ochi. (2008) "Mechanical properties of kenaf fibers and kenaf/PLA composites". Mechanics of materials, 40 (4-5), pp 446-452. 